\title{
A COMPARATIVE STUDY OF ENDOSCOPIC VERSUS OTOMICROSCOPIC MYRINGOPLASTY
}

Bishow Tulachan, ${ }^{1}$ Roshan Acharya, ${ }^{1}$ Buddha Nath Borgohain ${ }^{1}$

\section{ABSTRACT}

\section{INTRODUCTION}

Myringoplasty is one of the common surgical procedures done for closure of perforated tympanic membrane. Traditionally, it used to be performed with the help of operating microscope, however, the rigid endoscopes are being popular nowadays. So, we are comparing the success of graft uptake between endoscopic versus otomicroscopic myringoplasty.

\section{MATERIAL AND METHODS}

This is a prospective, comparative and randomized study done in the Department of Otorhinolaryngology and Head and Neck Surgery (ORL-HNS), Universal College of Medical Sciences-Teaching Hospital (UCMS-TH), Bhairahawa, Nepal. The study duration was for 18 months ( $\left(1^{\text {st }}\right.$ December 2015 to $31^{\text {st }}$ May 2017). There were 60 patients with age range of $12-$ 60 years. All the patients fulfilling the inclusion criteria were included. Patients were randomized into Group A (endoscopic) and Group B (otomicroscopic).

\section{RESULTS}

Patient's age ranged from 12-60 years. The mean \pm standard deviation (S.D) of age (years) between two groups was 27.07 \pm 11.96 years and $27.20 \pm 9.65$ years respectively. There were $33.33 \%$ male and $66.67 \%$ female patients in group A and $43.33 \%$ male and $56.67 \%$ female patients in group B. The graft uptake success rate was $93.33 \%$ in group A and $90 \%$ in group B. Statistically no significant difference was observed in graft success and failure rates between two groups ( $\mathrm{p}=$ $0.640)$

\section{CONCLUSION}

Comparatively the rate of graft uptake was higher in endoscopic group without statistical significance. Thus, endoscopic myringoplasty can be a good alternative of microscopic myringoplasty.

KEY WORDS Chronic otitis media, endoscopic, myringoplasty, otomicroscope

1. Department of ENT-Head and Neck Surgery, Universal College of Medical Sciences, Bhairahawa, Nepal

DOI: https://doi.org/10.3126/jucms.v6i2.22469

\author{
For Correspondence \\ Dr. Bishow Tulachan \\ Department of ENT-Head and Neck Surgery \\ Universal College of Medical Sciences \\ Bhairahawa, Nepal \\ Email: tulachanbishow@hotmail.com
}




\section{INTRODUCTION}

Chronic otitis media (COM) is defined as a longstanding inflammatory condition of the middle ear and mastoid associated with or without a perforation of the tympanic membrane (TM). ${ }^{1}$ Browning classified COM disease into five types in 1997 - COM Squamous active, COM Squamous inactive, COM Mucosal active, COM Mucosal inactive and Healed $\mathrm{COM}^{2}{ }^{2} \mathrm{TM}$ perforation with no associated middle ear inflammation and discharge is classified as COM mucosal inactive. ${ }^{3}$

Treatment (both oral and topical antibiotics) are prescribed during active stage of $\mathrm{COM}^{4}$ while the surgical closure of perforated pars tensa of TM known as myringoplasty is done only in inactive stage. Small perforations might have spontaneous resolution while large perforations occupying more than $50 \%$ of pars tensa require myringoplasty.

Berthold ${ }^{7}$ coined the term 'myringoplasty' in 1878 and used free skin graft for TM closure. Wullstein and Zollner popularized it by introducing various tympanoplasty techniques in 1953. Among various grafting materials (fascia, perichondrium, vein, duramater and cartilage), temporalis muscle fascia is the most frequently used grafting material and majority of recent studies have reported graft success rate of $60-99 \%$ in adults. ${ }^{8}$

Traditionally, the operating microscope has been in use for myringoplasty. It provides a magnified image in straight line; hence the surgeon can't visualize the deep recesses of the middle ear in single operating field. So, the rigid endoscopic technique of myringoplasty are becoming more popular these days. ${ }^{9}$ Endoscopic technique was first introduced by Mer and colleagues in 1967 but till the last decade endoscopes have been mainly used for diagnostic and photographic purposes. ${ }^{10}$ Advantages of endoscopic technique are that the hidden areas that cannot be seen under a microscope can be better observed with different angles, allows for functional reconstruction and anatomical protection, provides a wider surgical view with good resolution, avoids post auricular incision and canalplasty. ${ }^{11}$

Perhaps, the greatest disadvantage in this technique is the onehanded nature of endoscopic ear surgery plus a lack of sufficient microscopic magnification and focus, frequent contamination of the surgical site secondary to bleeding, and instrument crowding within the surgical area. ${ }^{12}$

This is a study of first kind in our institute, so it will help us to decide better on which surgery to be undertaken. The present study was conducted to determine the outcomes of endoscopic-assisted myringoplasty and microscopic myringoplasty in terms of graft uptake and to compare result between them.

\section{MATERIAL AND METHODS}

This study was conducted in the department of ORL-HNS, UCMS-TH, Bhairahawa, Nepal from 1st December 2015 to 31st May 2017. This is a prospective, comparative and randomized study. It was approved by the Institutional Review Committee of UCMS-TH. Non-probability, convenient sample selection technique was used.

For the sample size determination, a biostatistician was consulted and was calculated by http://www. survey system.com. A total of 67 myringoplasties were performed during 18 months prior to the study period in the department of ORL-HNS, UCMS-TH, Bhairahawa. Taking this figure as population, with confidence level of $95 \%$ and confidence interval of $5 \%$, the sample size calculated was 57 . However, with the feasibility to get more cases, we have increased the sample size to 60. Inclusion Criteria: i) patients of dry mucosal type of COM, ii) age between 11years and 60 years, iii) patients of all genders. Exclusion criteria: i) patients with complications of chronic otitis media, ii) patients with revision myringoplasty, iii) active ear discharge within last one month prior to surgery, iv) age less than 11 years and more than 60 years, v) patients with cholesteatoma.

Patient attending OPD with the inclusion criteria fulfilled were recruited for the study. Pre operational investigations as per guidelines of department of anesthesiology, UCMS-TH were done followed by assessment for fitness for general anesthesia (GA).

Informed and written consents were obtained from the patient (above 18 years) and the caregivers (18 or less) explaining the two types of procedure used prior to the surgery. All patients were admitted in the evening before the day of operation and a calculated dose of preoperative intravenous antibiotic (injection ceftriaxone: $50 \mathrm{mg} / \mathrm{kg}$ every 12 hours) were administered on the night before the operation.

The patients were divided into two groups i.e., Group A: Endoscopic myringoplasty and Group B: Otomicroscopic myringoplasty through randomization. The distribution was performed by OPD nurse unaware of the purpose of the study. Detail history, general physical examination, ear examination with otoscope and tuning fork test with $512 \mathrm{~Hz}$ were done. Examination under microscope was done before surgery.

\section{Surgical procedure}

Of the total 60 patients, 54 (90\%) patients underwent surgery under GA and the remaining $6(10 \%)$ under local anesthesia (LA). GA was administered according to the standard 
protocol. Injection glycopyrrolate $0.005 \mathrm{mg} / \mathrm{kg}$ was given followed by IV fentanyl $1 \mu \mathrm{g} / \mathrm{kg}$ as analgesia. Induction was done with IV propofol $2 \mathrm{mg} / \mathrm{kg}$. Injection vecuronium $0.1 \mathrm{mg} / \mathrm{kg}$ for muscle relaxation was given. Intubation was done. Anesthesia was maintained with $1.2 \%$ isoflurane in oxygen and controlled ventilation. LA patients were premedicated with intramuscular injections of $50 \mathrm{mg}$ pethidine and $25 \mathrm{mg}$ phenergan. In both methods, EAC was anesthetized using injection 2\% xylocaine with 1:20,0000 adrenaline at a dose of $7 \mathrm{mg} / \mathrm{kg}$ at 3-O clock, 6-O clock, 9-O clock and 12-O clock positions at bony cartilaginous junction. All the operations were strictly performed by the senior surgeons who were familiar with both the techniques.

\section{Technique of endoscope assisted myringoplasty}

Zero degree $4 \mathrm{~mm}, 17 \mathrm{~cm}$ rigid endoscopes were used (Figure 1)

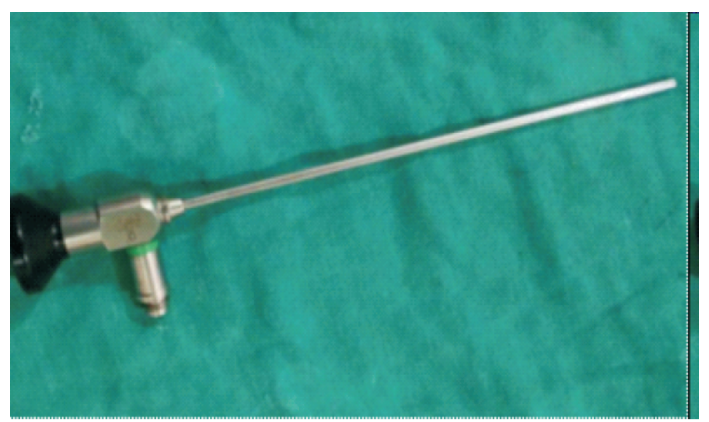

Figure 1. Zero degree $4 \mathrm{~mm}$ wide $17 \mathrm{~cm}$ long Hopkins rod endoscope.

All surgeries were done by visualization using the monitor (Figure 2). The endoscope was held in the left hand and instrument in the right hand, no endoscope holder was used.

Approach the route was permeatal for all endoscope assisted myringoplasties. All were purely endoscopic and at no point of time the microscope was used. All patients had a $2 \mathrm{~cm}$ incision in the hairline just above the helix to harvest the temporalis fascia graft.

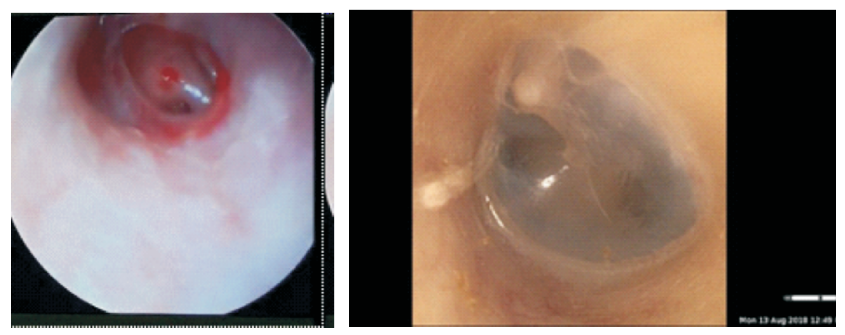

Figure 2. Endoscopic image (a) showing perforation in the tympanic membrane and (b) well taken up graft after 3 months
Margins of the perforation was freshened using straight needle as to break the adhesions formed between the squamous margin of the ear drum with that of the middle ear mucosa. This was followed by scraping of under surface of the TM round the perforation. A $6 \mathrm{O}^{\prime}$ clock and $12 \mathrm{O}$ 'clock incision was made in the tympanomeatal region by Plester knife then using a round knife, a curvilinear incision was made about $5 \mathrm{~mm}$ lateral to the annulus and the incision was extended between the 1-o clock, 3-O clock and 7-O clock positions in the left ear and 11-o clock, 9-O clock and 5-O clock positions in the right ear. The flap was meticulously elevated away from the bone of the external canal up to the level of annulus. Then ossicular chain, chorda tympani nerve and middle ear mucosa inspected. The temporalis fascia graft was placed in such a manner that it extends under the margin of perforation, handle of malleus and annulus and a small part should also extend over the posterior canal wall (underlay technique). Tympanomeatal flap was then reposited back. Abgel was placed in the middle ear and ear canal followed by ear pack (ribbon gauze) impregnated with antibiotic and steroid ointment (neomycin and belcomethasone) ointment and mastoid pressure bandage.

\section{Technique of microscope assisted myringoplasty}

The two approaches postaural or permeatal which ever allowed better exposure was used. The temporalis fascia or tragal perichondrium graft was harvested; the rest procedure being similar to endoscopic approach.

Postoperatively, patients were given oral antibiotics and antihistaminic for 7 days and analgesics (Ibuprofen 400mg + Paracetamol 500mg 8 hourly) for 3 days or more as needed. Dressing was changed next day. Follow up was done in $7^{\text {th }}$ post- operative day (POD) and after 6-8 weeks of surgery. In $7^{\text {th }}$ POD, suture and pack were removed. Topical antibiotic and steroid ear drops were given for 2 weeks. Patients were followed at or after $6^{\text {th }}$ to $8^{\text {th }}$ weeks. Graft uptake result was noted. Residual perforation of any size from pin point to total rejection was reported as failure.

\section{Data entry and analysis}

Data entry was done by using Microsoft excel 2010 and was analyzed using Statistical Package for Social Service version 20 (SPSS 20). Biostatistician was consulted. Data analysis was done using chi-square test. A p-value of less than 0.05 was taken to be statistically significant.

\section{RESULTS}

Demographic variables including age group, gender distribution in both groups is summarized in Table 1. No statistically significant difference noted in gender wise distribution 
in both methods $(\mathrm{p}=0.596)$. The maximum number of cases fall in the age group 21-30 years with frequency of 10 $(33.33 \%)$ in group A and $12(40 \%)$ in group B, followed by 9 $(30 \%)$ in group A and $10(33.33 \%)$ in group B in age groups $11-20$ years. The minimum frequency of $1(3.33 \%)$ was seen in age groups 41-50 years in both groups. There was no statistically significant difference noted in age wise distribution between the two groups $(\mathrm{p}=0.597)$ (Table 1). The mean age group was 27.07 (years) in group A and 27.20 in group B without significant statistical difference $(\mathrm{p}=0.962)$.

Table 1. Classification of cases on basis of demographic variables

\begin{tabular}{|c|c|c|c|c|c|}
\hline & \multicolumn{2}{|c|}{ Number of cases } & \multicolumn{2}{|l|}{ Percentage } & \multirow{2}{*}{$\mathrm{p}$-value } \\
\hline $\begin{array}{l}\text { Age group } \\
\text { (years) }\end{array}$ & Endoscopic & Otomicroscopic & Endoscopic & Otomicroscopic & \\
\hline $11-20$ & 9 & 10 & 30 & 33.3 & \multirow[t]{5}{*}{0.597} \\
\hline $21-30$ & 10 & 12 & 33.3 & 40 & \\
\hline $31-40$ & 9 & 5 & 30 & 16.6 & \\
\hline $41-50$ & 1 & 1 & 3.3 & 3.3 & \\
\hline $51-60$ & 1 & 2 & 3.3 & 6.6 & \\
\hline Sex & & & & & \multirow[t]{3}{*}{0.596} \\
\hline Male & 10 & 13 & 33.3 & 43.3 & \\
\hline Female & 20 & 17 & 66.6 & 56.6 & \\
\hline
\end{tabular}

Table 2. Distribution of patients based on graft materials in endoscopic and otomicroscopic groups

\begin{tabular}{|l|l|l|l|}
\hline Graft & Endoscopic $\mathrm{n}(\%)$ & Otomicroscopic $\mathrm{n}(\%)$ & $\mathrm{p}$-value \\
\hline Temporalis fascia & $30(100)$ & $27(90)$ & 0.76 \\
\cline { 1 - 3 } Tragal perichondrium & $0(0)$ & $3(10)$ & \\
\hline
\end{tabular}

Use of graft materials in both groups is summarized in Table 2.There were no statistically significant difference noted $(\mathrm{p}=$ $0.76)$.

Table 3. Distribution of patients based on laterality in endoscopic and otomicroscopic groups

\begin{tabular}{|l|l|l|l|}
\hline Ear side & Endoscopic n (\%) & Otomicroscopic n (\%) & p-value \\
\hline Right & $16(53.33)$ & $18(60)$ & 0.795 \\
\cline { 1 - 3 } Left & $14(46.67)$ & $12(40)$ & \\
\hline
\end{tabular}

Laterality of ear in both groups is summarized in Table 3. There was no statistically significant difference noted $(\mathrm{p}=$ $0.795)$.

Table 4. Distribution of patients based on approach in endoscopic and otomicroscopic groups

\begin{tabular}{|l|l|l|}
\hline Approach & Endoscopic n (\%) & Otomicroscopic n (\%) \\
\hline Permeatal & $30(100)$ & $22(73.33)$ \\
\hline Postaural & $0(0)$ & $8(26.66)$ \\
\hline
\end{tabular}

Approach selection for both groups is summarized in table 4 .

Table 5. Distribution of patients based on graft success and failure rates in endoscopic and otomicroscopic groups

\begin{tabular}{|l|l|l|l|}
\hline Graft uptake & Endoscopic n (\%) & Otomicroscopic n (\%) & p-value \\
\hline Failure & $2(6.67)$ & $3(10)$ & 0.640 \\
\hline Success & $28(93.33)$ & $27(90)$ & \\
\hline
\end{tabular}

It showed that there were $28(93.33 \%)$ success rates in endoscopic groups and $27(90 \%)$ in otomicroscopic groups. The failure rates in endoscopic group were $2(6.67 \%)$ and that of otomicroscopic groups was $3(10 \%)$. There was no statistically significant noted in graft success and failure rates between two groups $(\mathrm{p}=0.640)($ Table 5$)$.

\section{DISCUSSION}

Myringoplasty is one of the commonest surgical procedures performed in the ENT practice. The present study was undertaken with the objective to assess and compare the success of the graft uptake between two groups.

The mean age group in our study was $27.07 \pm 11.96$ years in endoscopic group and $27.20 \pm 9.65$ years in microscopic group. However, both group had mean age belonging to early adulthood (twenties) which is the common age group who undergo myringoplasty procedure as described by other studies. ${ }^{13,14}$ In this study, there were $10(33.33 \%)$ male and 20 $(66.67 \%)$ female patients in endoscopic group and 13 $(43.33 \%)$ male and $17(56.67 \%)$ female patients in otomicroscopic group similar to other studies. ${ }^{13,14}$ There was no statistically significant difference noted in age wise distribution in both methods.

As per our study, no difference in gender distribution were noted in other studies as well. Himani L. et $\mathrm{al}^{15}$ included 60 patients of age greater than 12 years with mean age of $28.30 \pm$ 9.39 years in the endoscopy group and $25.53 \pm 8.38$ years in the microscopy group. In his study, $50 \%$ of patients were female in the endoscopy group whereas $57 \%$ were female in the microscopy group. Lakpathi G. et $\mathrm{al}^{16}$ included 60 patients of age range from 15 to 55 years. Majority $(70 \%)$ of our patients were in their second and third decades of life.

In our study, the graft take rates were comparable between groups, $93.3 \%$ and $90.2 \%$ for groups A and B respectively. Graft failure was found in two patients in group A and in three patients in microscopic group. There was no statistically significance noted in graft success and failure rates between two groups ( $p=0.640)$. Our result was in concurrence with the result of Raj A et al ${ }^{17}$ and not in concurrence with the result of Harugop AS et al. ${ }^{18}$ In study done by Raj A et al ${ }^{17}(\mathrm{n}=40)$, there was $90 \%$ uptake of graft in the endoscopic group and $85 \%$ in 
microscopic group whereas graft uptake was seen in $82 \%$ in endoscopic and $86 \%$ in microscopic group in the study done by Harugop AS et al $(n=100) .{ }^{18}$ Comparison of graft uptake, however, is questionable as it depends on a host factors, surgical experience, choice of approach (postaural, transcanal), Eustachian tube function and graft material (cartilage/fascia). ${ }^{17}$ In Sudarshan L et $\mathrm{al}^{16}(\mathrm{n}=60)$ study, the success rate in term of graft uptake was comparable between two groups with no statistical significance.

Our study would have been even better with a larger sample size, longer follow up period, all the surgeries performed by the single surgeon and comparison of other parameters like hearing result, duration of surgery.

\section{CONCLUSION}

In our study, the success rate of graft uptake via endoscope assisted myringoplasty was comparable to that of microscopic myringoplasty. However, no statistically significance noted in graft success and failure rates between two groups. Thus, endoscopic myringoplasty can be a good alternative of microscopic myringoplasty.

\section{CONFLICT OF INTEREST}

There is no conflict of interest.

\section{REFERENCES}

1. Fisch U, May JS, Linder T. Tympanoplasty, Mastoidectomy, and Stapes Surgery, 2nd ed. Ann R Coll Surg Engl. 2010 ; 92 (1) $: 81$.

1. Browning GG, Merchant SN, Kelly G, Swan IR, Canter R, McKerrow WS. Chronic otitis media. Scott-Brown's otorhinolaryngology, head and neck surgery, 7 th en. 2008;3: $3395-401$

2. Knapik M, Saliba I. Pediatric myringoplasty: a study of factors affecting outcome. International Journal of Pediatric Otorhinolaryngology. 2011;75(6):818-23.

3. Schuknecht H. Pathology of the ear. 2nd. Philadelphia, Pa: Lea and Febiger. 1993;191-253.

4. Lasisi AO, Olaniyan FA, Muibi SA, Azeez IA, Abdulwasiu KG, Lasisi TJ, Imam ZO, Yekinni TO, Olayemi O. Clinical and demographic risk factors associated with chronic suppurative otitis media. International Journal of Pediatric Otorhinolaryngology. 2007;71(10):1549-54.

5. Little P, Bridges A, Guragain R, Friedman D, Prasad R, Weir N. Hearing impairment and ear pathology in Nepal. The Journal of Laryngology \& Otology. 1993;107(5):395-400.

6. Tong MC, Yue V, Ku PK, Van Hasselt CA. Preoperative topical ofloxacin solution for tympanoplasty: a randomized, controlled study. Otology \& Neurotology. 2002;23(1):18-20.

7. Slattery WH. Pathology and clinical course of inflammatory diseases of the middle ear. Glasscock-Shambaugh surgery of the ear. 2003;5:428-9.

8. Sudhakar PJ, RAO. Endoscopic myringoplasty/type 1 tympanoplasty. Indian Journal Of Applied Research. 2017;7(4) :106-7.

9. Sismanis A. Tympanoplasty GlasscockShambaugh surgery of the ear. 5th ed.Ontario: BC Decker Inc; Hamilton. 2003;463-85.

11. Zollner F. The principles of plastic surgery of the soundconducting apparatus. The Journal of Laryngology \& Otology. $1955 ; 69(10): 637-52$.

12. Yearsley J. Deafness practically illustrated. London. Churchill \& Sons; 1863.

13. Aftab A, Shamsheer A, Shahab F H, Syed AH. A Prospective Study Comparing the Results of Endoscope Assisted Versus Microscope Assisted Myringoplasty. Glob J Oto. 2016; 1(4): $1-6$.

14. Gaur RS, Tejavath P, Chandel S. Comparative study of microscopic-assisted and endoscopic-assisted myringoplasty. Indian J Otol 2016;22:177-82.

15. Takahashi H, Sato H, Nakamura H, Naito Y, Umeki H. Correlation between middle-ear pressure-regulation functions and outcome of type-I tympanoplasty. Auris Nasus Larynx. $2007 ; 34(2): 173-6$.

16. Lakpathi G, Reddy LS. Comparative Study of Endoscope Assisted Myringoplasty and Microscopic Myringoplasty. Indian Journal of Otolaryngology and Head \& Neck Surgery. 2016;68(2):185-90.

17. Raj A, Meher R. Endoscopic transcanal myringoplastya study. Indian Journal of Otolaryngology and Head \& Neck Surgery. 2001;53(1):47-9.

18. Harugop AS, Mudhol RS, Godhi RA. A comparative study of endoscope assisted myringoplasty and micrsoscope assisted myringoplasty. Indian Journal of Otolaryngology and Head \& Neck Surgery. 2008;60(4):298-302. 